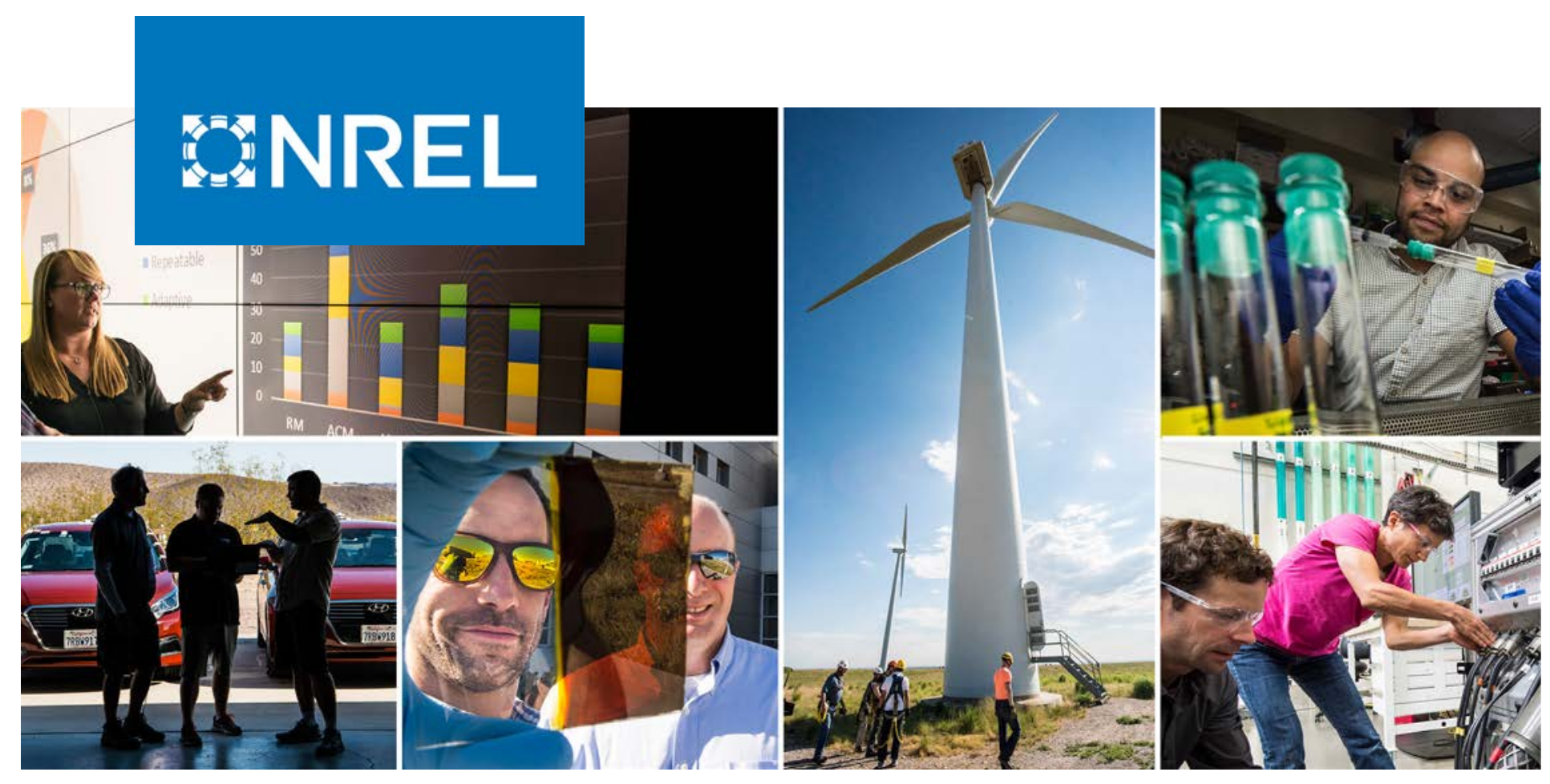

\title{
Potential Infrastructure Cost Savings at Hybrid Wind Plus Solar PV Plants
}

Aaron Barker, Parangat Bhaskar, Benjamin Anderson, and Annika Eberle

National Renewable Energy

NREL is a national laboratory of the U.S. Department of Energy

Office of Energy Efficiency \& Renewable Energy

Operated by the Alliance for Sustainable Energy, LLC

This report is available at no cost from the National Renewable Energy Laboratory (NREL) at www.nrel.gov/publications.
Technical Report

NREL/TP-5000-78912

December 2021 


\title{
GNREL
}

\section{Potential Infrastructure Cost Savings at Hybrid Wind Plus Solar PV Plants}

\author{
Aaron Barker, Parangat Bhaskar, Benjamin Anderson, and \\ Annika Eberle
}

National Renewable Energy

\author{
Suggested Citation \\ Barker, Aaron, Parangat Bhaskar, Benjamin Anderson, and Annika Eberle. 2021. \\ Potential Infrastructure Cost Savings at Hybrid Wind Plus Solar PV Plants. Golden, CO: \\ National Renewable Energy Laboratory. NREL/TP-5000-78912. \\ https://www.nrel.gov/docs/fy22osti/78912.pdf
}

NREL is a national laboratory of the U.S. Department of Energy Office of Energy Efficiency \& Renewable Energy Operated by the Alliance for Sustainable Energy, LLC

This report is available at no cost from the National Renewable Energy Laboratory (NREL) at www.nrel.gov/publications.

Contract No. DE-AC36-08GO28308
Technical Report

NREL/TP-5000-78912

December 2021

National Renewable Energy Laboratory 15013 Denver West Parkway Golden, CO 80401

303-275-3000 • www.nrel.gov 


\section{NOTICE}

This work was authored by the National Renewable Energy Laboratory, operated by Alliance for Sustainable Energy, LLC, for the U.S. Department of Energy (DOE) under Contract No. DE-AC36-08GO28308. Funding provided by the U.S. Department of Energy Office of Energy Efficiency and Renewable Energy Wind Energy Technologies Office. The views expressed herein do not necessarily represent the views of the DOE or the U.S. Government.

This report is available at no cost from the National Renewable Energy Laboratory (NREL) at www.nrel.gov/publications.

U.S. Department of Energy (DOE) reports produced after 1991 and a growing number of pre-1991 documents are available free via www.OSTI.gov.

Cover Photos by Dennis Schroeder: (clockwise, left to right) NREL 51934, NREL 45897, NREL 42160, NREL 45891, NREL 48097, NREL 46526.

NREL prints on paper that contains recycled content. 


\section{Executive Summary}

Hybrid power plants (HPPs) have the potential to increase the value of renewable energy systems and decrease their costs through shared development (e.g., permitting) and infrastructure (e.g., collection system). Prior work has identified potential cost savings and technical and economic performance improvements for solar-plus-storage plants; however, additional research is needed to understand cost drivers that are specific to wind-based HPP. Here, we analyze the potential for shared infrastructure cost savings at one type of hybrid plant: wind plus solar photovoltaic $(\mathrm{PV})$. The baseline comparison in this considers the co-located HPP versus a "virtual" HPP. In this comparison we are considering only costs and not operational capability; therefore the virtual HPP can be considered to be functionally equivalent in cost terms to a combination of single-generation (wind plus solar PV) technologies, and thus these findings hold true for the comparison of hybrid vs non-hybrid plants. We further examine the cost scaling of wind and solar PV Balance of System (BOS) components alone, as well as in a HPP scenario. To perform this analysis, we developed a new, open-source, Python-based cost modeling tool: the Hybrid Balance-of-System (BOS) Systems Engineering model (HybridBOSSE). Our baseline cost assumptions reveal potential cost savings of $11.8 \%$ in BOS costs (reflective of an approximate saving of $4 \%$ of the total cost of a wind + solar plant) for a co-located 200-MW wind-plus-solar PV hybrid plant (100 MW of wind plus 100 MW of solar PV) versus a "virtual" (not co-located) 200MW wind-plus-solar PV plant. At certain plant sizes (50MW), savings in BOS can reach as much as $16 \%$. We also show that the greatest cost reductions from physical component sharing come from substation and grid connection and that the potential for cost savings is highly dependent on project size (impacting both total project costs and percentage cost savings). We make a number of assumptions regarding reduction in soft costs (such as management, development, permitting) reductions based on early industry feedback, and we model the impact these assumptions have on the cost saving opportunity in HPPs. We hope that this will provide a starting point for broader industry discussion around the cost savings possible in HPPs, and we encourage further feedback to refine and update these assumptions as the industry matures. This work demonstrates that HPPs provide additional value from a cost saving perspective, and provides the tools for developers and academia to analyze the cost impact of their own assumptions around HPP costs. The methods and results presented here demonstrate a new capability to identify which HPP scenarios offer the greatest cost-reduction opportunities as well as providing open source modeling capabilities to the broader community of developers and researchers alike. 


\section{Acknowledgements}

This work was authored by the National Renewable Energy Laboratory, operated by Alliance for Sustainable Energy, LLC, for the U.S. Department of Energy (DOE), under Contract No. DE-AC36-08GO28308. Funding provided by U.S. Department of Energy Office of Energy Efficiency and Renewable Energy Wind Energy Technologies Office. The views expressed in the article do not necessarily represent the views of the DOE or the U.S. Government. The authors are solely responsible for any omission or errors contained herein. 


\section{Contents}

Executive Summary $\ldots \ldots \ldots \ldots \ldots \ldots \ldots \ldots \ldots \ldots \ldots \ldots \ldots$

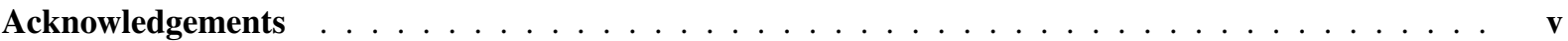

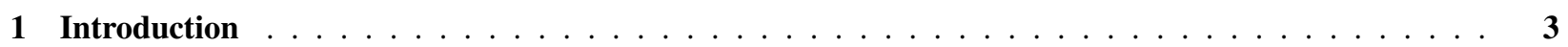

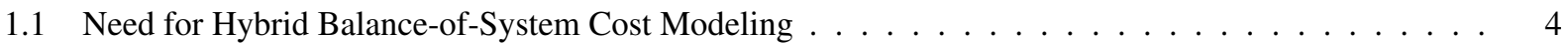

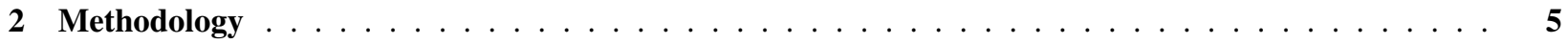

2.1 Defining a Baseline Hybrid Wind-Plus-PV Power Plant $\ldots \ldots \ldots \ldots \ldots \ldots$

2.2 Developing a BOS Cost Model for Hybrid Power Plants . . . . . . . . . . . . . . . . . 7

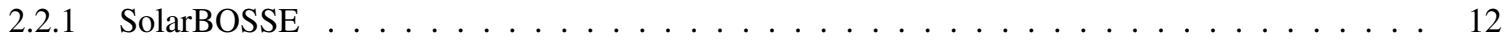

2.3 Shared Infrastructure Analysis Scenarios . . . . . . . . . . . . . . . . . . . . . . . . . . . . 14

2.4 Cost Scaling Study . . . . . . . . . . . . . . . . . . . . . . . . . . 15

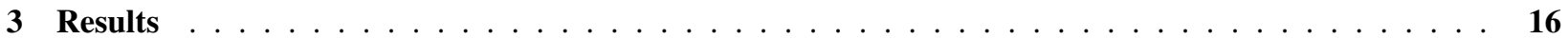

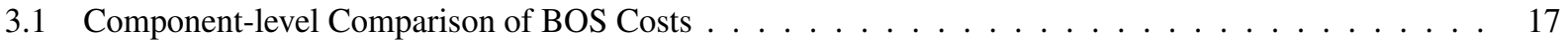

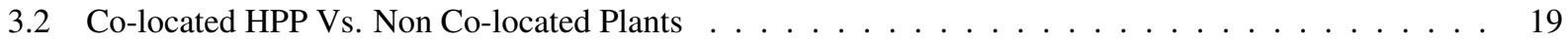

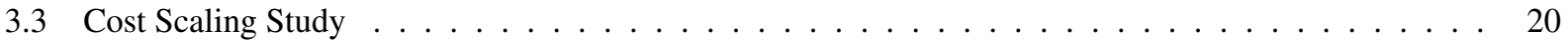

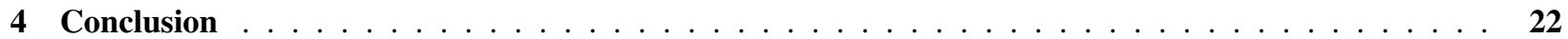

\section{List of Figures}

Figure 1. Baseline architecture for a virtual wind-plus-solar PV hybrid plant, including BOS components . 5

Figure 2. Baseline architecture for a wind-plus-solar PV HPP, including BOS components . . . . . . . 6

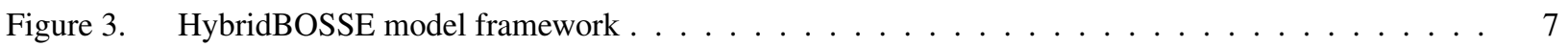

Figure 4. BOS components included in the LandBOSSE, SolarBOSSE, and StorageBOSSE models _ . . 9

Figure 5. Solar module mounting structure design reference used in SolarBOSSE (1 Solar Table) . . . . . . 13

Figure 6. Sample system architecture of a solar PV array used in SolarBOSSE . . . . . . . . . . . . . . . . 14

Figure 7. Sample wind farm array design used in LandBOSSE . . . . . . . . . . . . . . . . . . . 14

Figure 8. BOS cost versus project rating for three types of power plants $\ldots \ldots \ldots \ldots$

Figure 9. Total project capital expenditures (CapEx) versus project rating for three types of power plants . . 16

Figure 10. Interconnection Costs for HPP by Project Installed Capacity ～. . . . . . . . . . . . . . 17

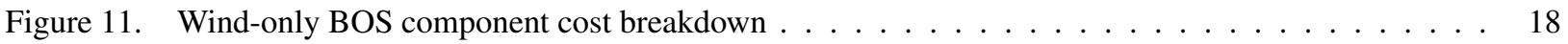

Figure 12. Solar-only BOS component cost breakdown $\ldots \ldots \ldots \ldots \ldots \ldots \ldots$

Figure 13. Wind-plus-solar PV HPP BOS component cost breakdown . . . . . . . . . . . . . . . . . . 19 
Figure 14. Potential BOS Component Cost Savings for Level III Hybridization of Wind-plus-solar PV . . . . 20

Figure 15. BOS costs for virtual (non-colocated) wind-plus-solar PV hybrid vs. a colocated wind-plus-solar

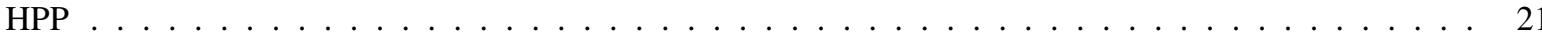

Figure 16. Potential for BOS cost savings at wind-plus-solar PV HPP as compared to a virtual (non-colocated)

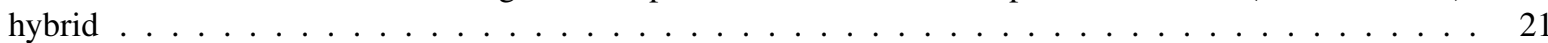

\section{List of Tables}

Table 1. Baseline technology configurations for each technology in our wind-plus-solar PV hybrid power

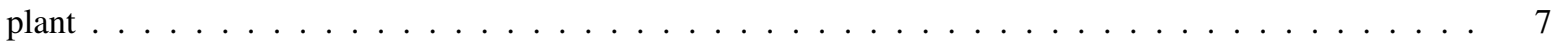

Table 2. Subset of HybridBOSSE model inputs used in this study . . . . . . . . . . . . . . . 8

Table 3. Potential for soft cost sharing via co-location by component/module . . . . . . . . . . . . . 10

Table 4. Type of cost sharing by component/module in HybridBOSSE . . . . . . . . . . . . . . 10

Table 5. Cost Sharing Assumptions in HybridBOSSE . . . . . . . . . . . . . . . . . 11

Table 6. Component cost-sharing assumptions for hybrid wind and solar PV plant . . . . . . . . . . . . 11

Table 7. Component breakdown of a single solar mounting table . . . . . . . . . . . . . . . 13

Table 8. List of parameters and parameter ranges explored in this study . . . . . . . . . . . . . . 15

Table 9. Potential cost savings by component for 200-MW wind-plus-solar PV virtual hybrid vs. a wind-plus-solar PV HPP using 100\% interconnection rating . . . . . . . . . . . . . . . . . . . . 19

Table 10. Potential cost savings by component for 200-MW wind-plus-solar PV virtual hybrid vs. a wind-plus-solar PV HPP using 50\% interconnection rating. . . . . . . . . . . . . . . . . . . 20 


\section{Introduction}

Achieving the high penetrations of renewable energy indicated to meet 2030 and 2050 decarbonization targets will require a significant increase in the pace of renewable energy deployment (Seltzer 2020), particularly for wind and solar photovoltaic (PV) technologies. New and expanded services within energy markets (ancillary services such as ramping, voltage control, reactive power, frequency control), increased siting opportunities for current technologies, and continued reductions in renewable energy capital costs will be needed to enable this transition. Hybrid power plants (HPPs), which comprise multiple generation and/or storage technologies (Murphy, Schleifer, and Eurek 2021), represent one promising choice to further these goals. Given existing transmission constraints, HPPs could help service increased demand for renewable energy by maximizing the usage of existing interconnection points, while maintaining grid stability and operational capability at least cost (Godoy-González, Gil, and Gutiérrez-Alcaraz 2020).

As the penetration of renewable energy technology increases, flexible and resilient sources of generation that can participate in ancillary services markets will become increasingly valuable. HPPs show great promise in increasing resilience and maintaining reliability across a broader range of weather/resource and demand conditions than do single technologies (Lian et al. 2019; Godoy-González, Gil, and Gutiérrez-Alcaraz 2020). There are significant technical challenges preventing wind and solar PV technologies alone from acting as baseload generation or from participating in these markets. The potential for renewable generation sources such as wind to act as a stable and consistent energy source can be constrained by the generation profile of the wind resource (Roy, Kedare, and Bandyopadhyay 2010). In addition, limitations to predictability and forecasting wind make it difficult to have an accurate forecast of the energy (Huber, Dimkova, and Hamacher 2014). Solar energy, though more predictable, is unable to generate energy at night or in times of intense cloud cover, which greatly increases the number of ramping events and the requirement for ramping services (Rosenkranz, Martinez-Anido, and Hodge 2016). This creates difficulty in addressing new markets (ancillary services, or industrial fuel production) that require more continuous and reliable load provision with these renewable technologies.

HPPs, as well as storage technologies, offer the potential to address the need for producing stable and consistent energy in the renewable energy market. Storage technologies have a large role to play in this in their own right (Murphy, Schleifer, and Eurek 2021), (Denholm et al. 2020), but the scope of this work extends only to wind plus solar PV projects, while work is ongoing to extend the cost modelling capability developed here to include storage.

When their generation profiles are complementary, co-located wind and solar PV can produce more consistent energy at daily and annual timescales (Lian et al. 2019). Combining energy sources with complementary generation profiles introduces the dual benefit of simultaneously increasing energy production and smoothing the overall energy provided from the plant (Pan, Gao, and Muljadi 2009). As a result, hybridization can improve power quality, availability, and reliability (Tina, Gagliano, and Raiti 2006) and can maximize the utility of the substation, interconnection, cabling, land, and other components.

At the end of 2020, wind, solar, and/or storage HPPs (includes wind + storage, pv + storage, wind + pv and wind + pv + storage) represented 4.6 gigawatt $(\mathrm{GW})$ of utility-scale power plants installed in the United States (Energy Storage News 2020), up from $3.16 \mathrm{GW}$ at the end of 2019 (Wiser et al. 2020). According to Wiser et. al, wind + pv with no storage represents a relatively small fraction of this, at $0.85 \mathrm{GW}$ of installed capacity, however a further $6.98 \mathrm{GW}$ are in the pipeline for deployment. In addition, when wind + battery, solar + battery and wind + solar + battery projects are included, there are $172.2 \mathrm{GW}^{1}$ of HPP capacity awaiting approval in the interconnection queues (Note: Wiser et. al note and acknowledge that not all of these proposed projects will necessarily be built). These numbers are likely to increase rapidly as market drivers such as increased transmission line costs and long project development queues push developers to maximally leverage current interconnection permits by building larger deployments with higher capacity factors (Klonari et al. 2019).

\footnotetext{
${ }^{1}$ In this data, the storage capacity is not always broken out from the generation capacity, and thus it is unclear how much generation capacity this represents.
} 


\subsection{Need for Hybrid Balance-of-System Cost Modeling}

The value proposition of HPPs for cost saving still carries a lot of uncertainty, and is yet to be extensively validated by developed projects. Doing so will require additional data, which are scarce at present. Developers are still evaluating the economic outcomes based on limited design and operation experience. Such assessments will require an improved (and more detailed) understanding of capital costs and BOS cost drivers in co-located HPPs than prior research provides.

Prior research on wind + solar PV HPPs to date has predominantly focused on non-grid-connected HPPs and has evaluated potential changes in the energy production profile of these systems without giving as much consideration to the construction or BOS (also known as balance-of-station and balance-of-plant) costs (Dursun et al. 2013) (Reichling and Kulacki 2008) (Ghose, El Shahat, and Haddad 2017), which can contribute approximately $30 \%$ of overall wind plant costs and as much as 70\% of solar pv plant costs (Eberle et al. 2019). For example, prior cost analysis of HPPs has typically used a broad parameter sweep on a plant-cost-per megawatt [MW] basis without detailed consideration of component-level BOS costs (Zhai et al. 2018).

With the recent surge in industry interest for developing HPPs at the utility scale (GE 2019) (UtilityDive 2019), there is an increasing need to assess the costs of utility-scale HPPs. As the nascent utility-scale HPP industry develops, modeling how BOS costs change with different hybrid plant configurations and identifying the savings achievable through leveraging shared infrastructure will be valuable for understanding the potential for cost reductions and for choosing the optimal hybrid plant configuration for a given project.

In this study, we perform a baseline analysis for a co-located 200-MW wind-plus-solar PV hybrid plant (100 MW of wind plus $100 \mathrm{MW}$ of solar PV) versus a "virtual" (meaning not co-located but potentially operated and controlled as a single plant) 200-MW wind-plus-solar PV hybrid plant to determine the savings achievable through co-location for a utility-scale plant and to elucidate the components that contribute most to these savings. This report only considers capital costs, not operating costs, revenue streams, or other costs or value that might be realized after the initial installation of the plant(s). As a result, the capital costs associated with the "virtual" hybrid discussed here is equivalent to the sum of the independent capital costs associated with two single-technology plants. We refer to this plant as a virtual HPP hereafter. However, it is important to emphasize that other post-installation costs and value need to be considered to accurately evaluate the opportunity for the virtual HPP described here, along with the other hybrid configurations that we discuss.

To analyze BOS costs for our baseline wind-plus-solar PV HPP, we developed a process-based, techno-economic model to assess BOS costs for HPPs called the Hybrid Balance-of-System Systems Engineering model (HybridBOSSE). This is a new, open-source, Python-based cost modeling tool (available at https://pypi.org/project/hybridbosse/) that enables us to execute this type of analysis. We also used the HybridBOSSE platform to conduct a detailed analysis of the potential advantages offered by these two hybrid plants at scales ranging from $2.5 \mathrm{MW}$ to $500 \mathrm{MW}$. The outputs from HybridBOSSE allow us to better understand shared infrastructure costs in hybrid projects. Additionally, the platform was designed in a flexible manner to allow for expansion to other types of hybrid systems. The results of this study demonstrate a new capability to identify which HPP scenarios offer the greatest flexibility and cost-reduction opportunities. The developed tool, HybridBOSSE, is provided as an open-source tool to give the broader community a framework in which to assess these cost-reduction opportunities at the component level. 


\section{Methodology}

The goals of this study are to understand the BOS cost drivers for wind-plus-solar PV HPPs and to identify opportunities for savings associated with shared infrastructure costs and other soft costs. To perform this analysis, we defined a baseline hybrid wind-plus-PV power plant for both non co-located plants (Figure 1), and physically connected (Figure 2) HPPs, and we executed the HybridBOSSE model for both baseline plant configurations to analyze BOS cost data by component to identify opportunities for sharing infrastructure and other soft costs in physically co-located HPP scenario versus a non co-located plant. We also explored how scaling the project size changes the results.

\subsection{Defining a Baseline Hybrid Wind-Plus-PV Power Plant}

A standard plant architecture for a wind-plus-PV power plant does not currently exist, though there appears to be a consensus on one of two options: 1) whole-plant-level interconnection sharing or 2) component-level sharing (e.g., PV arrays connected per wind turbine) (Klonari et al. 2019) (Murphy, Schleifer, and Eurek 2021). We chose to focus on whole-plant-level interconnection sharing, as it is currently the most common form of hybridization adopted by project developers. Accordingly, the system studied in this work connects the wind and solar components downstream at the substation 2). As technology improves, the prevalence of component-level sharing may increase, and future work will look to add additional capabilities to HybridBOSSE for component-level sharing in HPPs.

Solar PV

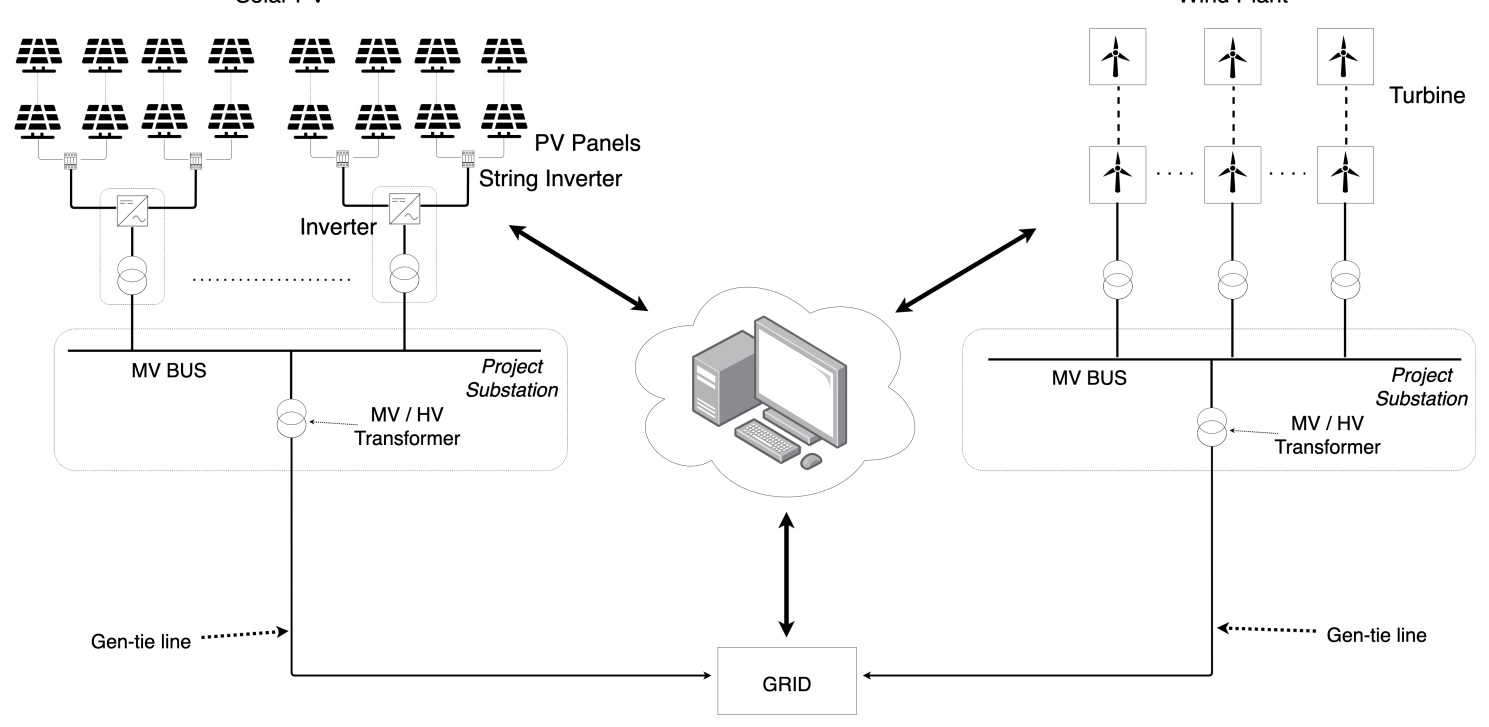

Figure 1. Baseline architecture for a virtual wind-plus-solar PV hybrid plant, including BOS components 


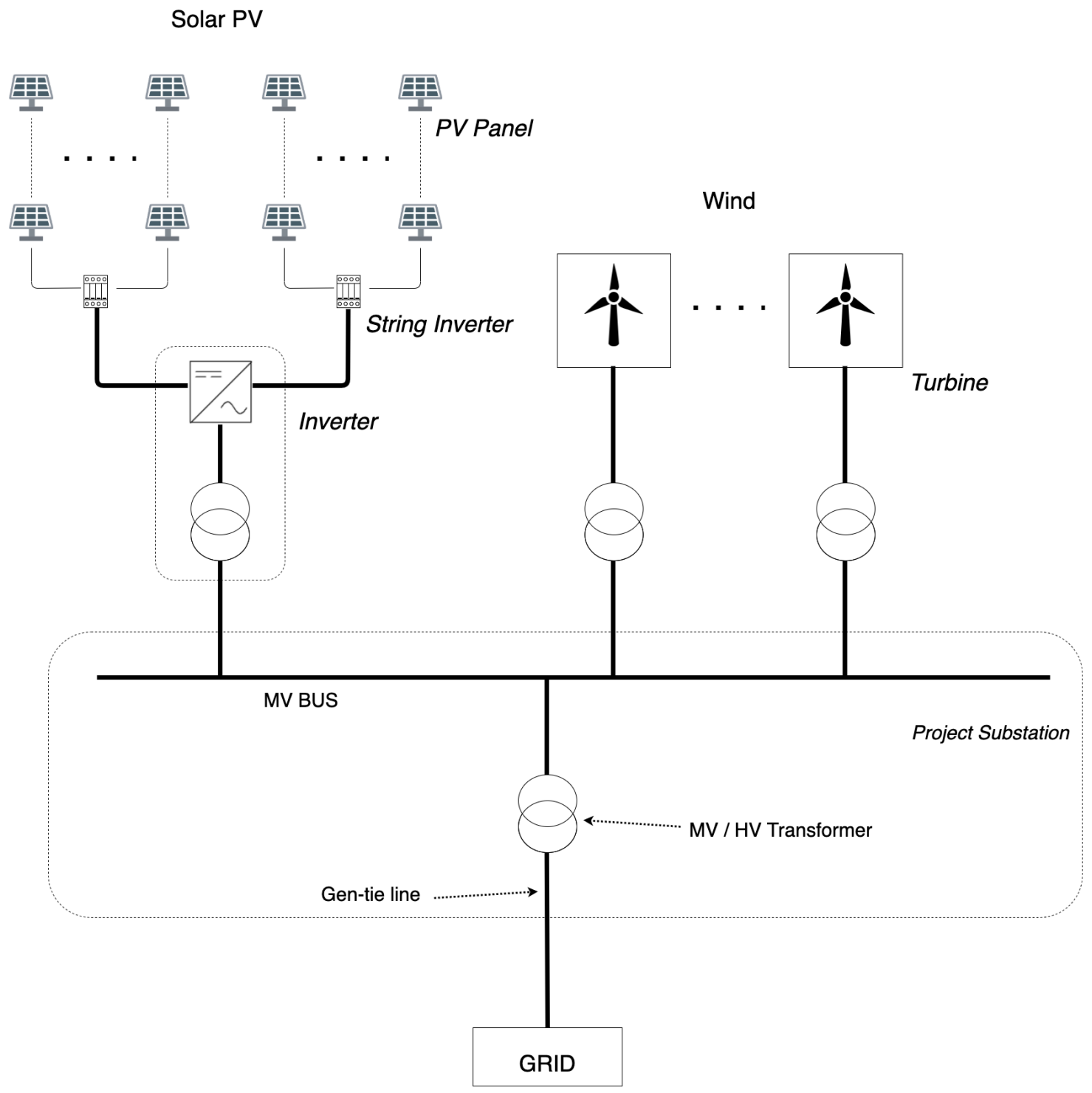

Figure 2. Baseline architecture for a wind-plus-solar PV HPP, including BOS components

We defined a baseline configuration for each technology in the HPP (Table 1). The baseline configuration of a wind power plant in the hybrid plant consists of a generic 2.5-MW wind turbine of 90-m hub height and 117-m rotor diameter (RD). The distance between turbines within each string is assumed to equal four times the rotor diameter; the distance between each string is seven times the rotor diameter. The solar PV array consists of a generic 375-W module, with an inverter rated at $1 \mathrm{MW}$, and a DC/AC ratio of 1.20. 
Table 1. Baseline technology configurations for each technology in our wind-plus-solar PV hybrid power plant

\begin{tabular}{llll}
\multicolumn{2}{c}{ Wind Power System } & \multicolumn{2}{c}{ Solar PV Power System } \\
Turbine rating (MW) & 2.5 & Module rating (W) & 375 \\
Hub height (m) & 90 & DC/AC ratio & 1.2 \\
Rotor diameter (m) & 117 & Modules per string & 14 \\
Turbine spacing (RD) & 4 & Inverter rating (MW) & 1 \\
Row spacing (RD) & 7 & Transformer rating (MW) & 1
\end{tabular}

Note: DC/AC Ratio of 1.2 is the default for NREL's SAM models on which

HOPP is based, and is in line with the assumptions of (EIA 2021) and others.

\subsection{Developing a BOS Cost Model for Hybrid Power Plants}

HybridBOSSE is an extension of the National Renewable Energy Laboratory's (NREL's) LandBOSSE model, which estimates the BOS cost of land-based wind power plants (Eberle et al. 2019), and it includes two new process-based BOS models: SolarBOSSE for utility-scale solar PV projects and StorageBOSSE for utility-scale battery energy storage projects. This study uses the SolarBOSSE and LandBOSSE modules; future work will explore the capabilities of StorageBOSSE in greater detail.

HybridBOSSE's framework is implemented in Python (see Figure 3). The main HybridBOSSE module pre- and postprocesses data and cost information. It accepts a set of user inputs (e.g., number of turbines, hub height, turbine rating, and solar PV system size). These inputs get redistributed to the individual BOS models of each technology (e.g., LandBOSSE and SolarBOSSE).

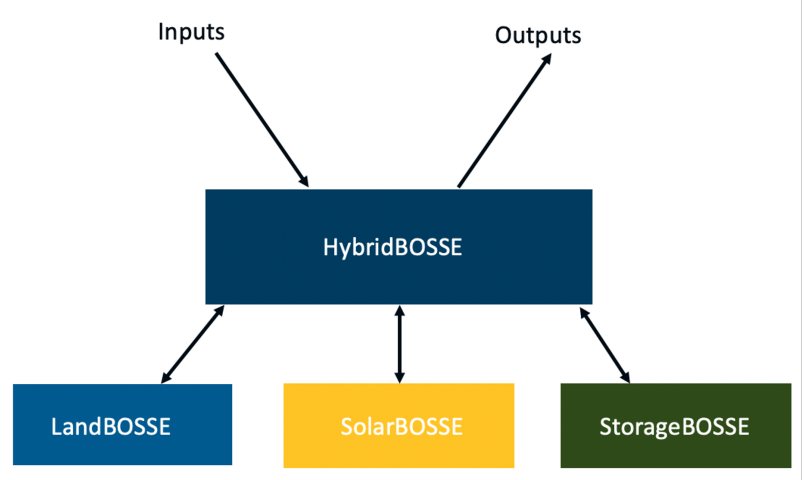

Figure 3. HybridBOSSE model framework

Note: Use of StorageBOSSE was outside the scope of this analysis.

HybridBOSSE accepts inputs that range from plant size and technology configuration to estimates for construction time (Table 2). For this analysis, however, we vary only a subset of 11 of these user inputs that are most relevant for hybrid plants (6 plant-level inputs, 3 wind plant inputs, and 2 solar array inputs). For the other model variables, we use a mix of proprietary industry data and publicly available data from (Eberle et al. 2019) (Stehly and Beiter 2019) (Vimmerstedt et al. 2019). 
Table 2. Subset of HybridBOSSE model inputs used in this study

\begin{tabular}{|l|l|l|}
\hline Technology & User Input & Notes \\
\hline \multirow{5}{*}{ Hybrid plant } & Shared interconnection & Determines whether technologies share interconnection \\
\cline { 2 - 3 } & Plant distance to grid interconnection (miles) & Distance of the utility's substation from the plant substation \\
\cline { 2 - 3 } & New switchyard & Will the plant substation require a new switchyard? \\
\cline { 2 - 3 } & Grid interconnection rating (MW) & Hybrid plant's grid interconnection rating \\
\cline { 2 - 3 } & Interconnection voltage (kV) & Hybrid plant's grid interconnection voltage \\
\cline { 2 - 3 } & Shared substation & Will all the technologies in the hybrid plant have a common substation? \\
\hline \multirow{3}{*}{ Wind plant } & Number of turbines & Number of turbines in the wind plant \\
\cline { 2 - 3 } & Turbine rating (MW) & Rated capacity of the wind turbine to use \\
\cline { 2 - 3 } & Wind construction time (months) & Time taken to construct the wind plant \\
\hline \multirow{2}{*}{ Solar PV array } & Solar array rating (MW) & DC rated capacity of the solar array \\
\cline { 2 - 3 } & Solar array construction time (months) & Time taken to construct the solar plant \\
\hline
\end{tabular}

Each BOS model consists of seven main cost modules: management development, substation, grid connection, site preparation, erection, collection system, foundation (see Figure 4). Each module consists of four main cost types: (1) labor, (2) equipment, (3) materials, and (4) other. The erection cost module includes the following additional cost line items: fuel cost and the cost of mobilization and demobilization. Figure 4 provides a breakdown of specific tasks within each module for all three technology types. 


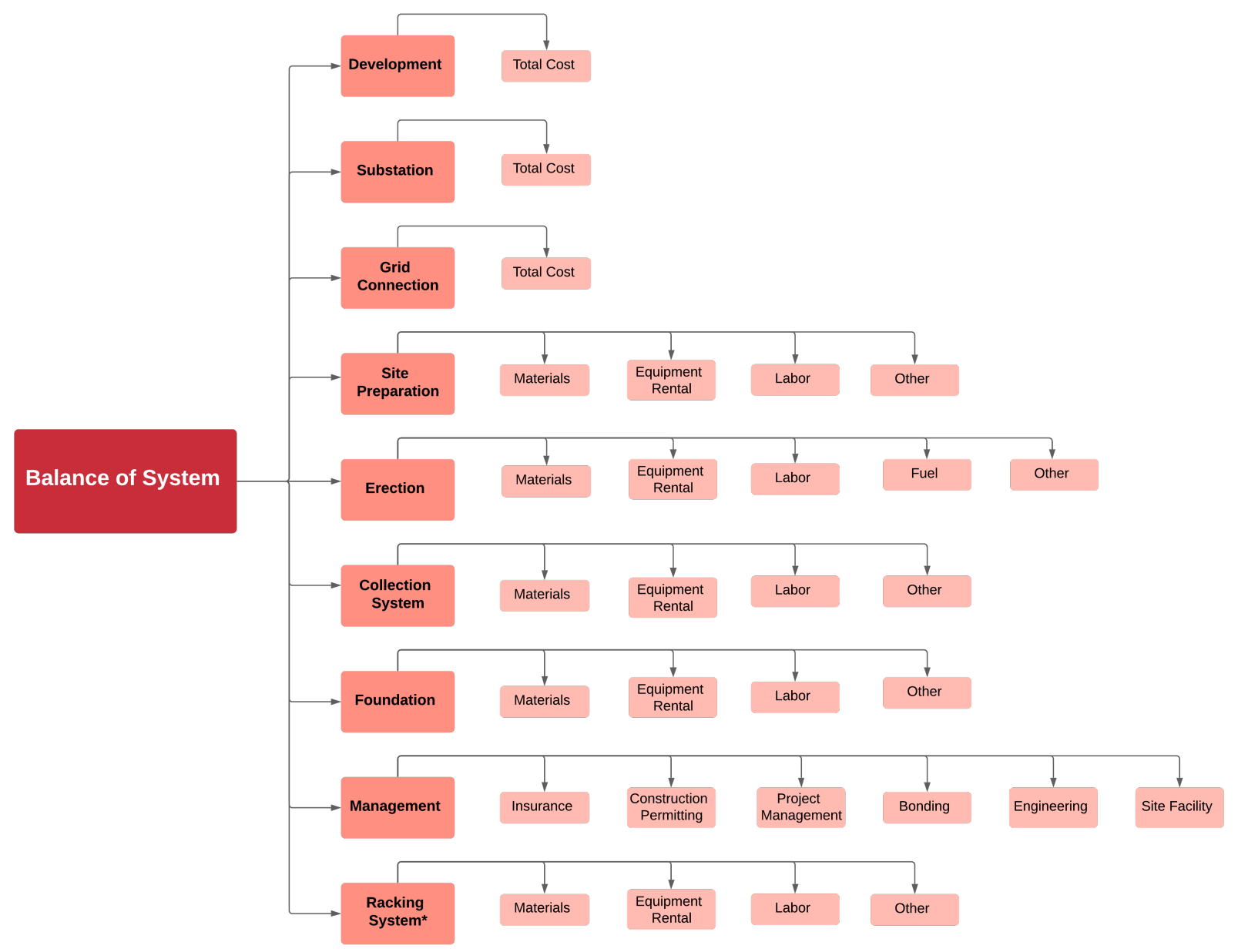

Figure 4. BOS components included in the LandBOSSE, SolarBOSSE, and StorageBOSSE models

Note: The racking system module is used only by SolarBOSSE to estimate the cost of procuring, transporting, and installing racking systems for PV modules

In our analysis, we compared each cost module across all technology combinations (colocated and non-colocated HPPs) to identify opportunities for sharing physical infrastructure and soft costs. See Table 3 , which summarizes the potential for sharing costs on a per-module basis. This estimate of potential for cost sharing is derived from aggregate data of talks with a large number of developers, where they were asked to comment on their expectations that these components would or should be shared in their hybrid plants. 
Table 3. Potential for soft cost sharing via co-location by component/module

\begin{tabular}{|l|c|c|c|}
\hline & \multicolumn{2}{|c|}{ Component Required } & Potential for Sharing \\
\hline \multicolumn{1}{|c|}{ BOS Component } & Wind Only & Solar PV Only & Wind + Solar PV Hybrid \\
\hline Foundation & yes & yes & n/a \\
\hline Site preparation & yes & yes & low \\
\hline Substation & yes & yes & high \\
\hline Grid connection (trans. dist.) & yes & yes & high \\
\hline Collection & yes & yes & n/a \\
\hline Erection & yes & yes & low \\
\hline Management development & yes & yes & high \\
\hline Module racking & no & yes & n/a \\
\hline
\end{tabular}

The level of detail considered for each component was not equal. For some components, the HybridBOSSE model is able to offer a full component analysis, meaning that each component cost is physically considered and costs are representative of, and derived from, the true physical configuration of the plant. For other components, such as project management and, to an extent, Substation and Grid/Interconnection costs, the model was forced to make "Soft Cost" assumptions that are merely representative of our expected savings based on industry conversations. This is noted in Table 4.

Table 4. Type of cost sharing by component/module in HybridBOSSE

\begin{tabular}{|l|l|}
\hline BOS Component & Type of Analysis \\
\hline Foundation & Full component \\
\hline Site preparation and roads & Full component \\
\hline Substation & Empirical/partial component \\
\hline Grid interconnect/transmission \& distribution & Empirical/partial component \\
\hline Cable collection system cost & Full component \\
\hline Erection system cost & Full component \\
\hline Project development and management & Soft cost \\
\hline Module racking & Full component \\
\hline
\end{tabular}

The analysis of a lower interconnection rating versus total project capacity rating in the hybrid scenario is predicated on the assumption that the complementarity of resource profiles between wind and solar allows for maximization of the utility of the interconnection, with greater effective utilisation and lower energy spill/curtailment than for a single technology. As this is a strategy that many developers have in mind, where permissible, we aimed to quantify the associated cost saving for this interconnection undersizing. 
Table 5. Cost Sharing Assumptions in HybridBOSSE

\begin{tabular}{|c|c|c|}
\hline Item & $\begin{array}{l}\text { Potential Cost Reduction } \\
\text { Through Sharing Wind } \\
\quad \text { \& Solar Tasks }\end{array}$ & Notes \\
\hline Project Insurance Costs & No & $\begin{array}{c}\text { Project insurance cost. } \\
\text { We assume minimal overlap in insurance costs } \\
\text { between Wind and Solar. }\end{array}$ \\
\hline Construction Permitting Cost & No & $\begin{array}{l}\text { Project construction permitting cost. } \\
\text { We assume minimal overlap in permitting } \\
\text { costs between Wind and Solar. }\end{array}$ \\
\hline Bonding Cost & No & $\begin{array}{l}\text { Project bonding cost. } \\
\text { We assume minimal overlap in bonding costs between Wind and Solar. }\end{array}$ \\
\hline Project Management Cost & No & $\begin{array}{l}\text { Project management cost includes QA/QC management, site managers, } \\
\text { administrative support, health and safety supervisors, } \\
\text { environmental supervisors, office equipment, site communication } \\
\text { and vehicles, per diem, legal and public relations. } \\
\text { We assume that there will be minimal cost reduction } \\
\text { opportunities in a HPP vs. Wind Only vs. Solar only. }\end{array}$ \\
\hline Mark-up and Contingency Cost & Yes & $\begin{array}{l}\text { Applies a percentage margin to all costs including hardware, } \\
\text { installation labor, EPC overhead, developer overhead, etc. } \\
\text { For a standalone Wind only or Solar only, } \\
\text { markup is } 5 \% \text { of total installed cost at } 100 \mathrm{MW}, \\
\text { and } 8 \% \text { of total installed cost at } 5 \mathrm{MW} \text {. } \\
\text { We assume that a saving opportunity for } \\
\text { a HPP will arise because the developer will charge a lower markup } \\
\text { for a } 100 \mathrm{MW} \text { HPP (50 MW Wind + } 50 \mathrm{MW} \text { Solar) compared to a } \\
\text { standalone } 50 \mathrm{MW} \text { Wind only or } 50 \mathrm{MW} \text { Solar only plant. }\end{array}$ \\
\hline Engineering and Design Cost & No & Site specific engineering costs for foundation and collection. \\
\hline Site Facility Cost & Yes & $\begin{array}{l}\text { Includes costs associated with building design and construction, } \\
\text { drilling and installing water well, including piping, } \\
\text { electric power for a water well, septic tank and drain field. } \\
\text { We assume common, shared site facility for HPP. }\end{array}$ \\
\hline Security Cost & Yes & $\begin{array}{l}\text { Includes costs associated with constructing and reinstating the compound, } \\
\text { branch plant site, restrooms, electrical and telephone hook-ups, } \\
\text { monthly office costs, signage, cattle guards and gates, access roads. } \\
\text { We assume common, shared site security for a HPP. }\end{array}$ \\
\hline
\end{tabular}

Note: These are assumptions we have made about the potential for cost sharing in hybrid plants. Individual projects may differ significantly from these assumptions.

To examine the impact of varying degrees of hybridization and colocation on the cost savings available, we explored three levels of cost sharing in our analysis (Table 6). In all cases, the wind and solar plants are colocated HPPs, configured as AC-DC connected plants with the configuration shown in Table 1. DC-DC connected plants were not considered in this study.

Table 6. Component cost-sharing assumptions for hybrid wind and solar PV plant

\begin{tabular}{|l|c|}
\hline Level & Components Shared \\
\hline I & Management, substation, grid connection \\
\hline II & I + site preparation \\
\hline III & II + crane (equipment only) cost \\
\hline
\end{tabular}

The levels I-III shown in Table 6 are intended to be reflective of the certainty that developers will avail of these cost saving opportunities when constructing a HPP, informed by discussions with industry. Each level adds additional component sharing which successively builds on the previous level - assuming that all of the prior level's components are shared in addition to the new component sharing proposed at this level.

\section{Level I:}


When colocating and wind + solar hybrids (locational and operational linkage) we assume, at a minimum, sharing of the same project substation, and the same grid interconnection cost. Here, grid interconnection includes costs pertaining to performing a land survey, clearing and grubbing the area, implementing stormwater pollution measures, installing the poles, installing the spur transmission (connecting the project to the grid), procuring and installing transformers and switchgear, and restoring the right of way.

We're also assuming that there will be some partial savings in the the management and development cost bucket via a co-located and co-developed project. Savings here could be achieved from a discount to the percentage expected EPC developer profit, which is typically 5-8\% (Fu, Feldman, and Margolis 2018) of the project value. This is a strategy that has been indicated by industry in hybrid plant developments as it 1) enables them to win marketshare 2) is associated with developing a larger project than would otherwise be possible at a given location.

Management savings could also be achieved from developer overhead, again following the same logic as EPC developer profit discount (individual technologies charging profit markup as though they're developing entire hybrid plant and not just an individual technology). Additional savings are assumed due to the use of the same (shared) site facility between wind and solar.

\section{Level II:}

Level II incorporates all Level I savings and additionally assumes leveraging sharing of equipment rental cost and mobilization cost (of labor, equipment, materials, etc.) in the site preparation cost bucket.

\section{Level III:}

Level III cost saving assumptions incorporate all Level II savings, while additionally leveraging sharing of equipment rental cost and mobilization cost of labor and equipment in the erection cost bucket.

The BOS and capital expenditure (CapEx) costs for wind and solar PV plants were determined at $100 \mathrm{MW}$ each, with component as described in Table 1. The hybrid plant was modeled with both of these individual plants combined on the medium-voltage bus (AC) level, for a total of $200 \mathrm{MW}$, with the configuration shown in Figure 2. The costs associated with each plant were then determined with interconnection sizing modeled at both $50 \%$ and $100 \%$.

\subsubsection{SolarBOSSE}

HybridBOSSE is an extension of the LandBOSSE model. Therefore, SolarBOSSE, a sub-model of HybridBOSSE, shares a majority of the same modules developed for LandBOSSE, including substation, grid connection, site-preparation, erection (used to estimate cost of erecting transformers and inverters), and foundation (used to estimate cost of constructing concrete pads for inverters and transformers). For a detailed review of key equations used in LandBOSSE, refer to (Eberle et al. 2019). The modules unique to SolarBOSSE are racking system, management, and collection system.

The racking system module of SolarBOSSE is used to estimate the total cost of installing mounting systems for solar PV modules, including labor, equipment, materials, and mobilization. We selected fixed-tilt ground mounted racking system for this analysis (see Figure 5). Using proprietary cost estimates of the individual components of solar table, the total material cost per table was estimated at $\$ 110 / \mathrm{kW}$ for a $1 \mathrm{MW}$ solar array. We assume that the price $(\$ / \mathrm{kW})$ of a solar table drops to $\$ 55 / \mathrm{kW}$ for a $500 \mathrm{MW}$ solar array (discounted price for large volume order). See Table 7 for a detailed breakdown of the components used per solar table. In SolarBOSSE, the racking system consists of a single repeating unit referred to here as a solar table; one solar table can hold 2 rows of PV modules, and $8 \mathrm{PV}$ modules per row, for a total of $16 \mathrm{PV}$ modules (2x8) per solar table. We assume that the table is sized for a generic $375 \mathrm{Watt} \mathrm{PV}$ module. Therefore, each solar table was rated at $6 \mathrm{~kW} /$ table. 


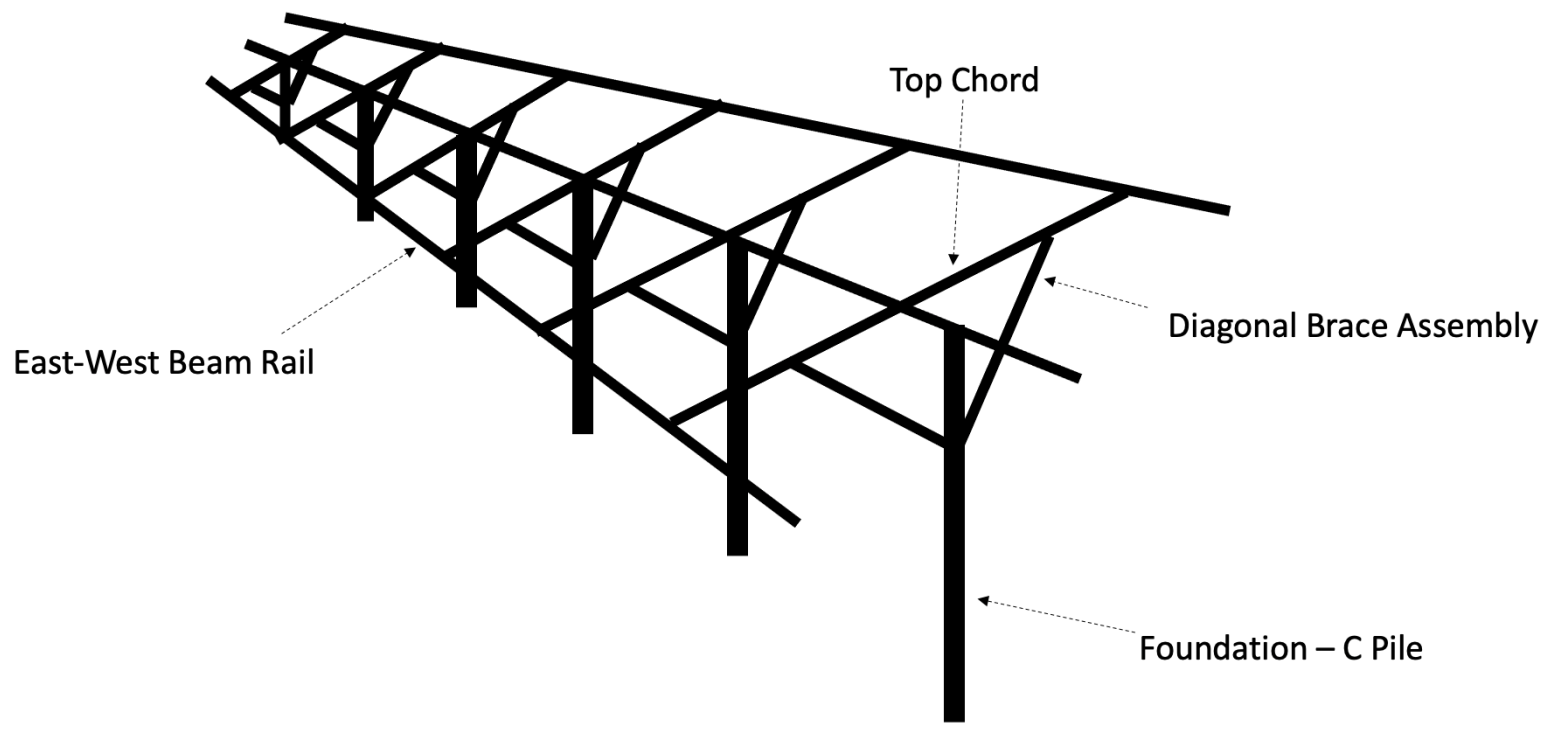

Figure 5. Solar module mounting structure design reference used in SolarBOSSE (1 Solar Table)

Table 7. Component breakdown of a single solar mounting table

\begin{tabular}{|l|c|l|}
\hline Part & Quantity per table & Notes \\
\hline Rail & 6 & Aluminum East-West beam (166" / unit) \\
\hline Splice kit & 3 & - \\
\hline Mid Clamp & 30 & $3 / 8$ " C clamp used \\
\hline End Clamp & 4 & 2 for east edge of table; 2 for west edge of table \\
\hline Foundation - C Pile & 3 & 12.5 feet \\
\hline Structure - Top Chord & 3 & GFT Top Chord Channel 20/30 SR - For Shared Rail Designs - Mill Finish (3.5 m) \\
\hline Structure - Diagonal Brace Assembly & 3 & - \\
\hline Assembly Hardware & - & $\begin{array}{l}\text { Assumed equivalent to 10\% of total cost of items 1 through 7 } \\
\text { (includes: nuts, bolts, washers, wire management ties, etc.) }\end{array}$ \\
\hline
\end{tabular}

Note: For this analysis, we assume that the table's foundation hole

is dug to a depth of 8 feet by a crane with a pile driver attachment.

SolarBOSSE's Collection module calculates the total cost (cost of labor, equipment, materials, and mobilization) of inter-array wiring of the solar PV system (wiring each module to the subarray's combiner box using DC cables), DC wiring from each combiner box to the subarray's inverter (includes cost of trenching), and medium voltage AC wiring from the subarray's LV/MV transformer to the project's substation. We assumed $14 \mathrm{PV}$ modules per string, 32 strings per combiner box, and subarray inverter rated at $1 \mathrm{MW}$. See Figure 6, for a high level representation of the system architecture of a utility-scale solar PV array design assumed in SolarBOSSE, and Figure 7 for a comparison with the system architecture of a wind farm. 


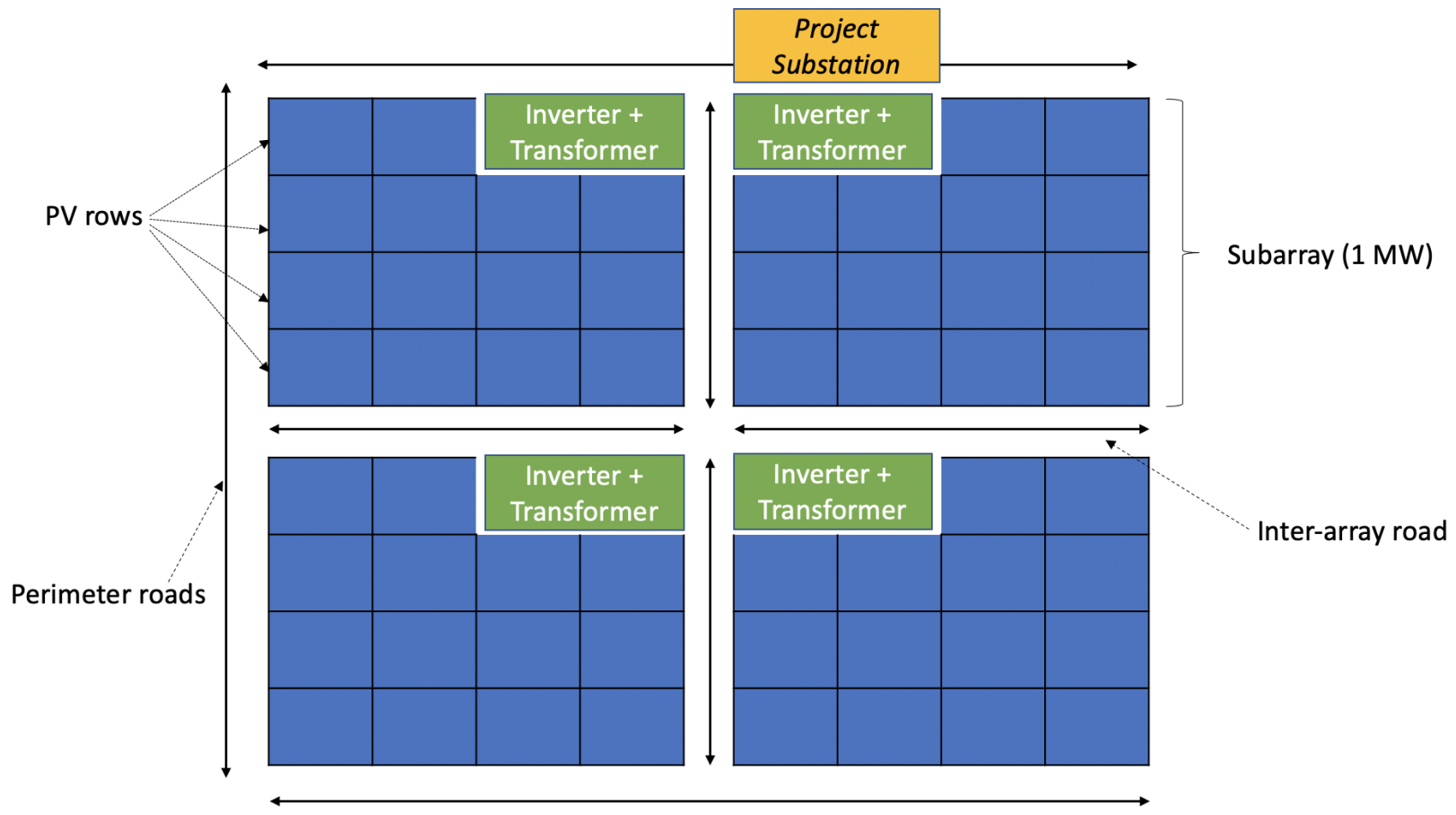

Figure 6. Sample system architecture of a solar PV array used in SolarBOSSE

Note: (1) We assume placement of one combiner box at the inner-end of each PV row. (2) We assume shallow trenches along either side of the inner-array road that runs North-South; wires from running from each combiner box to the subarray's inverter are buried in their corresponding trench and the trench is then back-filled with earth.

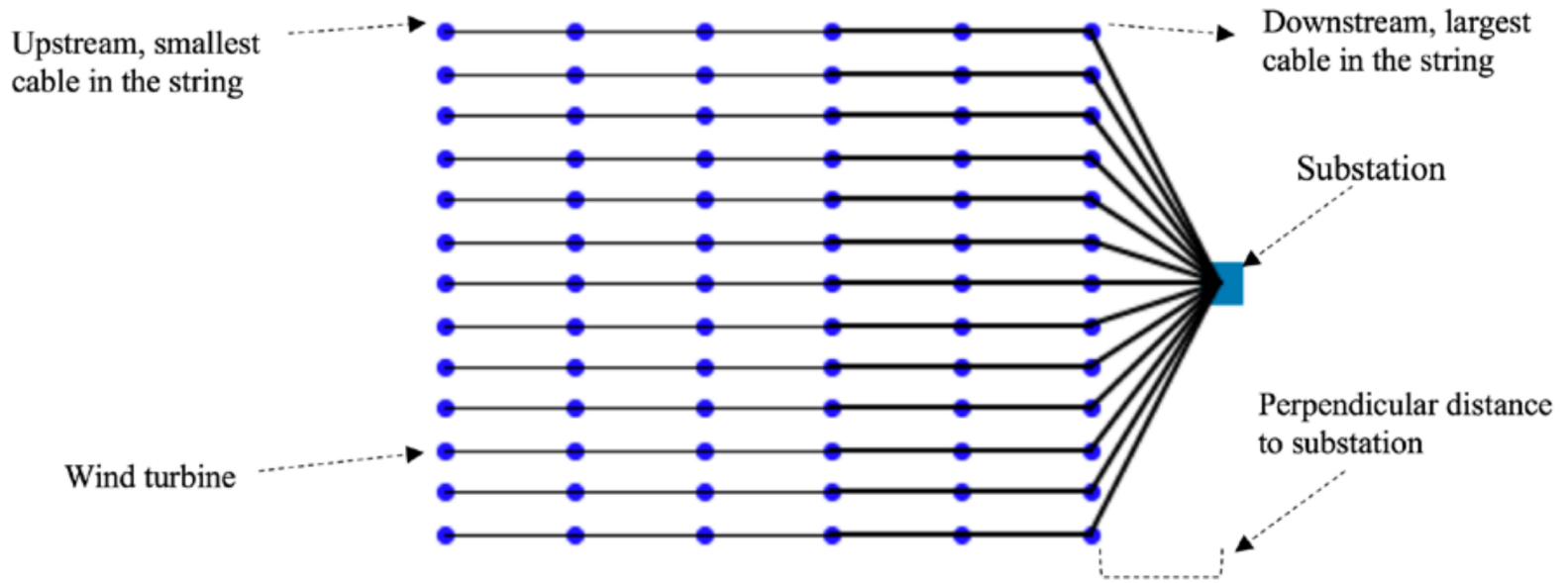

Figure 7. Sample wind farm array design used in LandBOSSE

\subsection{Shared Infrastructure Analysis Scenarios}

The analysis conducted in this work consisted of determining the BOS cost for a 100-MW wind-only plant, a 100-MW solar-only plant, and a 200-MW wind and solar PV hybrid plant comprising a combined $100 \mathrm{MW}$ of wind and 100MW of solar PV on both a 200-MW interconnection and a 100-MW interconnection. As addressed in the introduction, we consider a "Virtual" HPP (without any operational analysis) and a colocated HPP to provide a comparison of wind 
plus solar PV at different locations, versus a true HPP. Three levels of cost sharing assumption (as given in Table 6) are explored. We assumed the cost of a $2.5-\mathrm{MW}$ wind turbine to be $\$ 1,067 / \mathrm{kW}$ and the combined cost of PV modules and the inverter to be $\$ 510 / \mathrm{kW}$ (Stehly and Beiter 2019) (Fu, Feldman, and Margolis 2018).

\subsection{Cost Scaling Study}

To determine which components represent the greatest potential for cost savings in a hybrid plant, we also examined the component-level scaling of the BOS cost according to project size for wind, solar PV, and our baseline wind-plussolar PV hybrid plant. The component cost-sharing assumptions made are outlined in Table 5. These help inform the cost savings available at different project sizes that can be achieved through hybridization and colocation and which components represent the most valuable sharing opportunities.

To explore how the BOS CapEx of a wind-plus-solar PV HPP scales compared with a wind-only and a solar PV-only power plant, and to discern the relative importance of each major BOS cost component in projects from a single turbine/small PV array to a large utility-scale, we ran HybridBOSSE for plant sizes ranging from $2.5 \mathrm{MW}$ (individual technology)/ $5 \mathrm{MW}$ (hybrid) to $500 \mathrm{MW}$ in increments of $2.5 \mathrm{MW}$. This represents the sizing range within which the majority of HPPs will be built. The upper limit of our analysis was constrained by a lack of cost-scaling information beyond the 500-MW level. At each project size, we assumed equal contribution to the total hybrid plant size from both wind and solar PV (50:50 wind:solar PV). We also ran a sensitivity on the grid interconnection rating at each project size, with the grid interconnection rating ranging from $50 \%$ of hybrid plant capacity to $100 \%$ of hybrid plant capacity, which represent technically realistic overbuild scenarios for HPPs, in increments of $10 \%$. The project construction time linearly increases from 5 months for a 10-MW HPP to 60 months for a 500-MW HPP. See Table 8 for a summary of the list of parameters explored in this study.

Table 8. List of parameters and parameter ranges explored in this study

\begin{tabular}{|c|l|}
\hline Input Parameter & Description \\
\hline \multirow{2}{*}{ Hybrid power plant rated capacity (MW) } & Total hybrid power plant capacity \\
\cline { 2 - 2 } & $\begin{array}{l}\text { Equals the rated capacity of the wind plant } \\
\text { + the DC capacity of the PV array }\end{array}$ \\
\cline { 2 - 2 } & $\begin{array}{l}\text { The rated capacity of the wind plant } \\
\text { is equal to the rated DC capacity of the PV array. }\end{array}$ \\
\hline Grid interconnection rating (MW) & Grid interconnection rating of the hybrid power plant \\
\hline Substation rating (MW) & Substation rating of the hybrid power plant \\
\hline Interconnect voltage (kV) & Voltage at which the plant is tied to the grid \\
\hline \multirow{2}{*}{ Hybrid power plant construction time (in months) } & Time taken to construct the hybrid project \\
\cline { 2 - 2 } & $\begin{array}{l}\text { Equals the time taken (in months) to construct } \\
\text { the wind plant + the time taken to construct the PV array. }\end{array}$ \\
\hline
\end{tabular}

Analyzing the component-level costs will enable greater understanding of the cost savings that can be leveraged through hybridization and the value that different scenarios of hybridization and component sharing can provide. 


\section{Results}

Using HybridBOSSE, we quantified potential cost reductions that could be realized through shared infrastructure at a hybrid wind-plus-solar PV plant. We performed a parametric sweep of plant sizes ranging from $2.5 \mathrm{MW}$ to $500 \mathrm{MW}$ for a stand-alone wind power plant, stand-alone solar PV array, and a wind-plus-solar PV HPP and compared their respective BOS costs. Figure 8 shows the comparison of the BOS CapEx of all three technology types. To put the trends for BOS costs into context, we compared them to the total CapEx of all three technologies (see Figure 9).

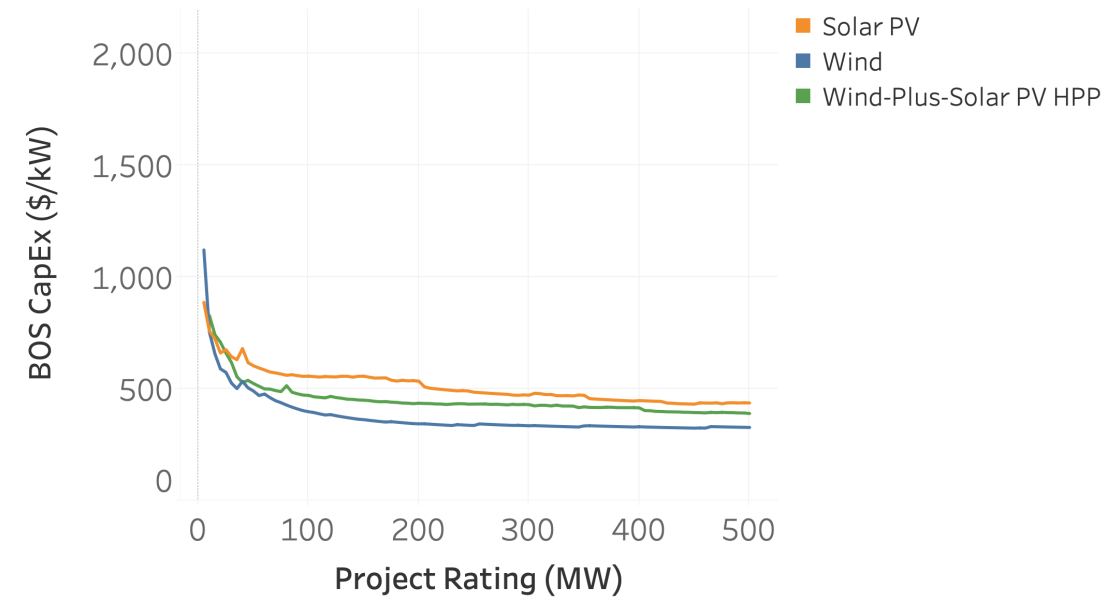

Figure 8. BOS cost versus project rating for three types of power plants

Note: The grid interconnection rating of the power plant equals the plant rating.

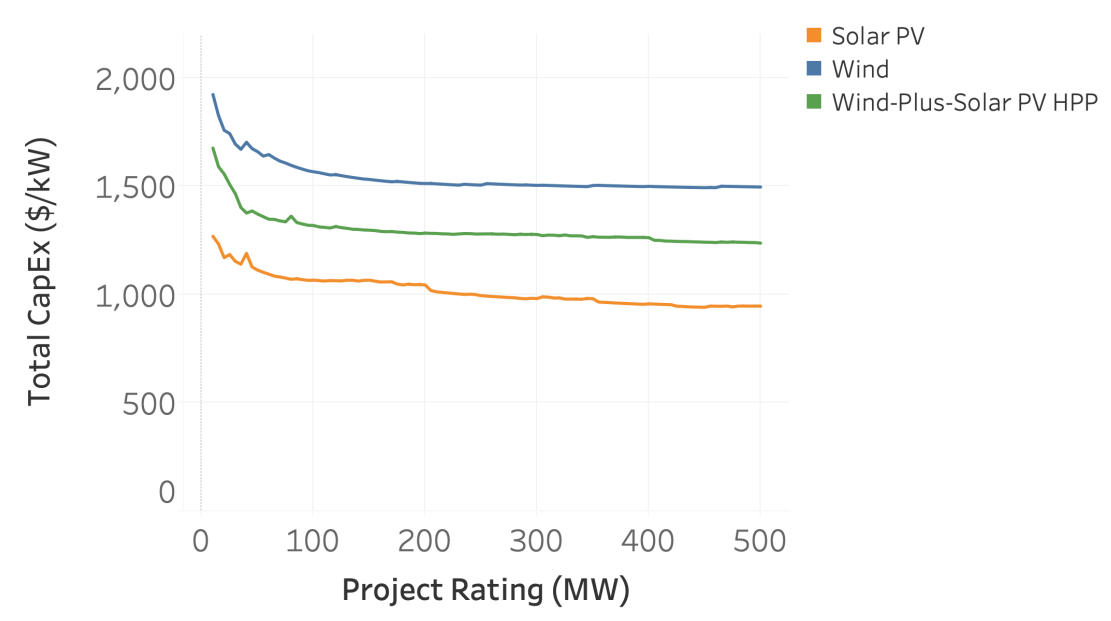

Figure 9. Total project capital expenditures (CapEx) versus project rating for three types of power plants

Note: The grid interconnection rating of the power plant equals the plant rating.

At the sub-25-MW scale, solar PV has the cheapest BOS CapEx, followed by the HPP and wind plant, respectively. The BOS CapEx of a wind power plant, however, decreases more rapidly with increasing installed capacity than the BOS CapEx of a solar PV plant; thus, wind has the lowest BOS CapEx $(\$ / \mathrm{kW})$ for plant sizes greater than $25 \mathrm{MW}$. Therefore, above this size, the colocated hybridization of the solar power plant reduces the BOS CapEx $(\$ / \mathrm{kW})$ of a solar PV plant but increases the BOS CapEx of a wind power plant. The relative degree of BOS savings (or cost 
increase), however, is dependent on plant architecture, interconnection voltage $(\mathrm{kV})$, and sharing of soft costs (namely, project management and development cost).

On a total project CapEx basis, wind is the most expensive technology, followed by HPPs, and solar respectively. The cost of hardware (i.e., the cost of the wind turbine, PV modules, and inverters) on average constitutes $77 \%$ of the total project CapEx $(\$ / \mathrm{kW})$ for HPPs; thus even large changes to BOS costs can have marginal impacts on overall project CapEx.

It is important to note that the results presented in Figure 8 assume that the grid interconnection rating of the HPP equals $100 \%$ of the project rating. In some cases, system operators may allow a generator to use an interconnection rating below the nameplate capacity of the generator (i.e., overbuild the project) (Kristian and Prorok 2020). If this happens, then the BOS of the HPP could also be slightly lower but the overall trends in BOS cost reductions as project rating increases remain similar.

\subsection{Component-level Comparison of BOS Costs}

To understand what drives these BOS cost trends, we examined the component-level contributions of each BOS cost category for these three plant configurations: wind-only, solar-only, and wind-plus-solar HPP (Figures 11, 12, and 13).

To examine the potential for cost saving via utilizing an interconnection with a rating below the nameplate capacity of the generator/plant, we analyzed the BOS CapEx cost for HPPs with project sizes of 10, 15, 30, 50, 75, and 100MW; with interconnection ratings of 100\%, $80 \%$ and $60 \%$ of the project size respectively (Figure 10). This analysis revealed cost reductions for HPPs with ratings of 10 and $15 \mathrm{MW}$; where the interconnection cost accounts for almost $20 \%$ of total BOS CapEx costs. Total BOS CapEx reduced from $\$ 833 / \mathrm{kW}$ with a $100 \%$ interconnection rating at $10 \mathrm{MW}$ to $\$ 770 / \mathrm{kW}$ with a $60 \%$ interconnection rating; and at a $15 \mathrm{MW}$ project rating, moving from $100 \%$ interconnection rating to $60 \%$ resulted in a reduction in total BOS CapEx from $\$ 750 / \mathrm{kW}$ to $\$ 667 / \mathrm{kW}$. At $30 \mathrm{MW}$ this saving begins to diminish, providing only a small benefit. The reduction in BOS cost at larger project sizes is proportionally smaller as a) the interconnection cost makes up a smaller fraction of the total BOS cost and b) there are economies of scale in interconnection pricing at larger sizes.

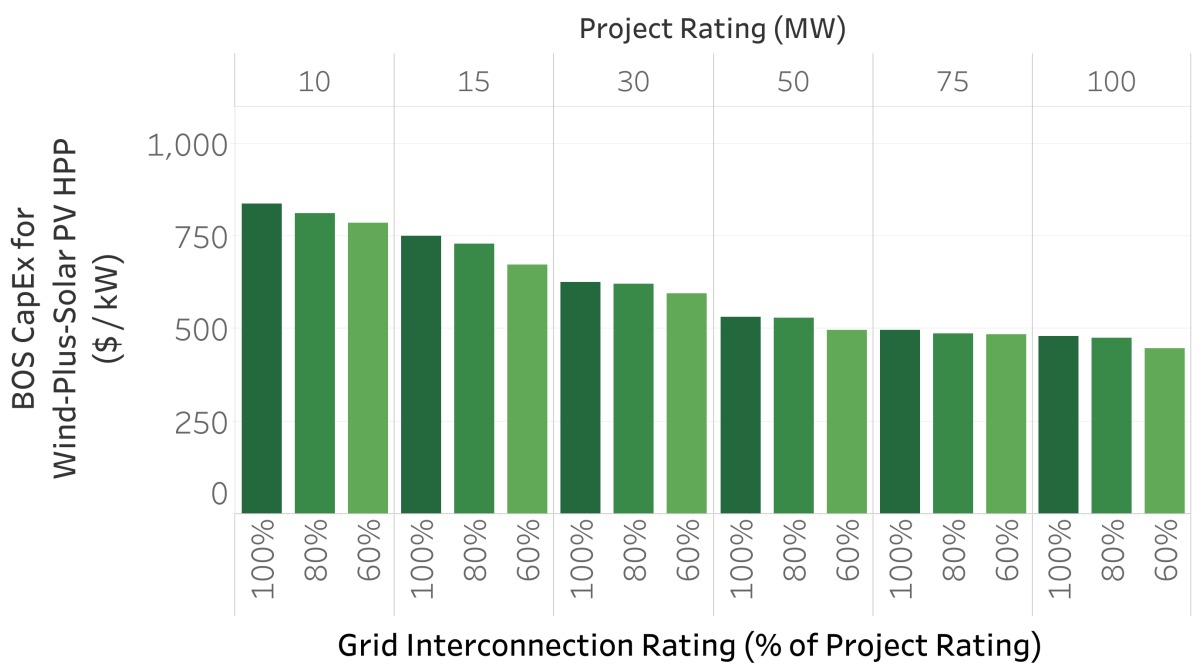

Figure 10. Interconnection Costs for HPP by Project Installed Capacity

Taking a broader overview of component level cost sharing potential, Figure 11 shows that the management and foundation costs represent the largest BOS cost categories for utility-scale wind-only projects. Management costs decrease (on a per-kilowatt $[\mathrm{kW}]$ basis) as project size increases. Foundation costs increase slightly with increasing project size (from $2.5 \mathrm{MW}$ to $10 \mathrm{MW}$ ) because of increased mobilization costs for larger plants. 


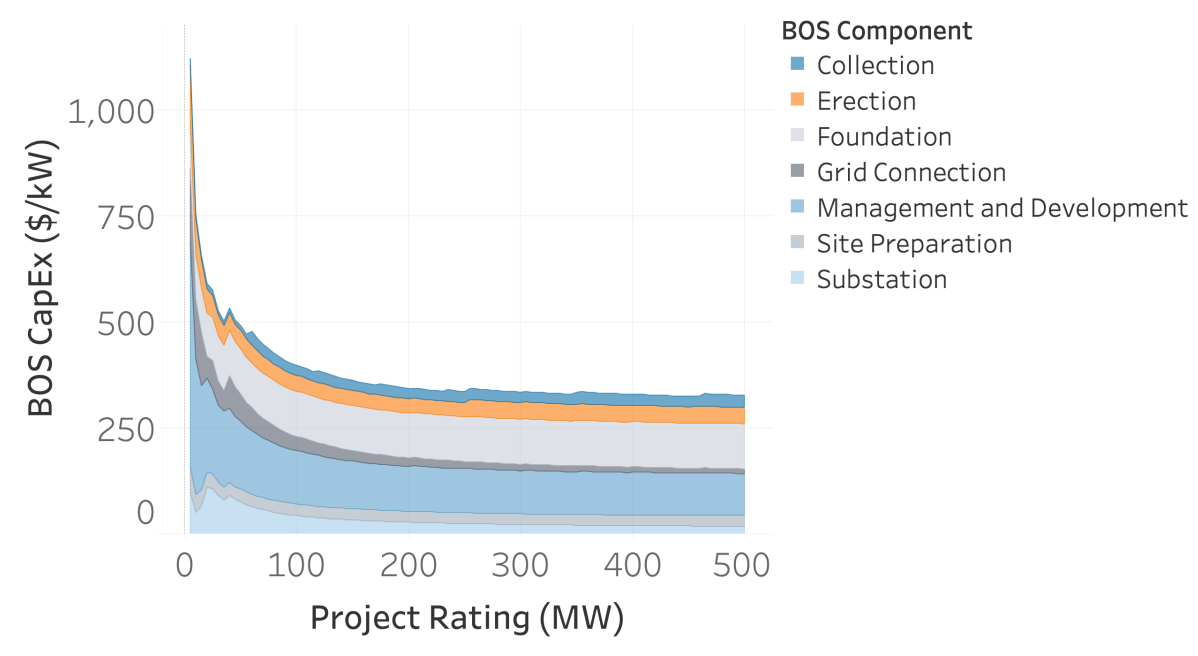

Figure 11. Wind-only BOS component cost breakdown

Figure 12 shows that the racking, management, and collection costs represent the largest cost categories for utilityscale solar PV-only projects. Of these costs, management and racking decrease in $\$ / \mathrm{kW}$ terms as project size increases. Collection costs represent the only category that sees increases on a $\$ / \mathrm{kW}$ basis as project size increases. This occurs because of increasing cable run distances.

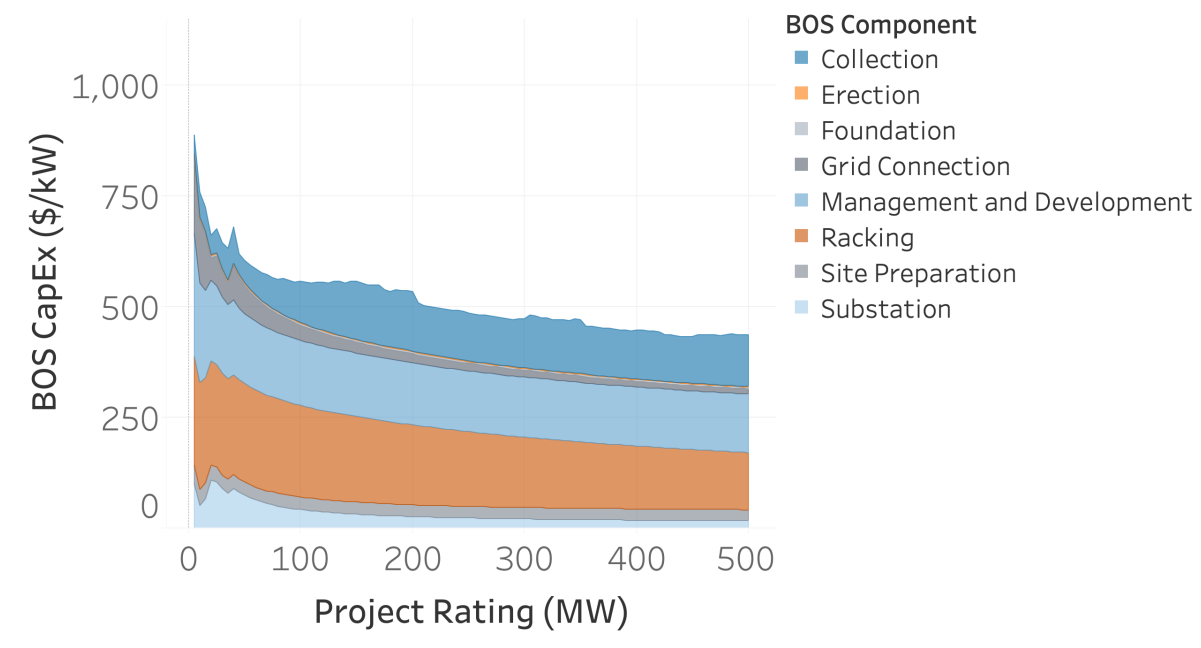

Figure 12. Solar-only BOS component cost breakdown

Examining the results of a hybrid wind-plus-solar PV plant (Figure 13), with components combined as shown in Figure 2 , reveals that the management and racking costs represent the largest $\$ / \mathrm{kW}$ BOS cost categories, with both decreasing as project size increases. 


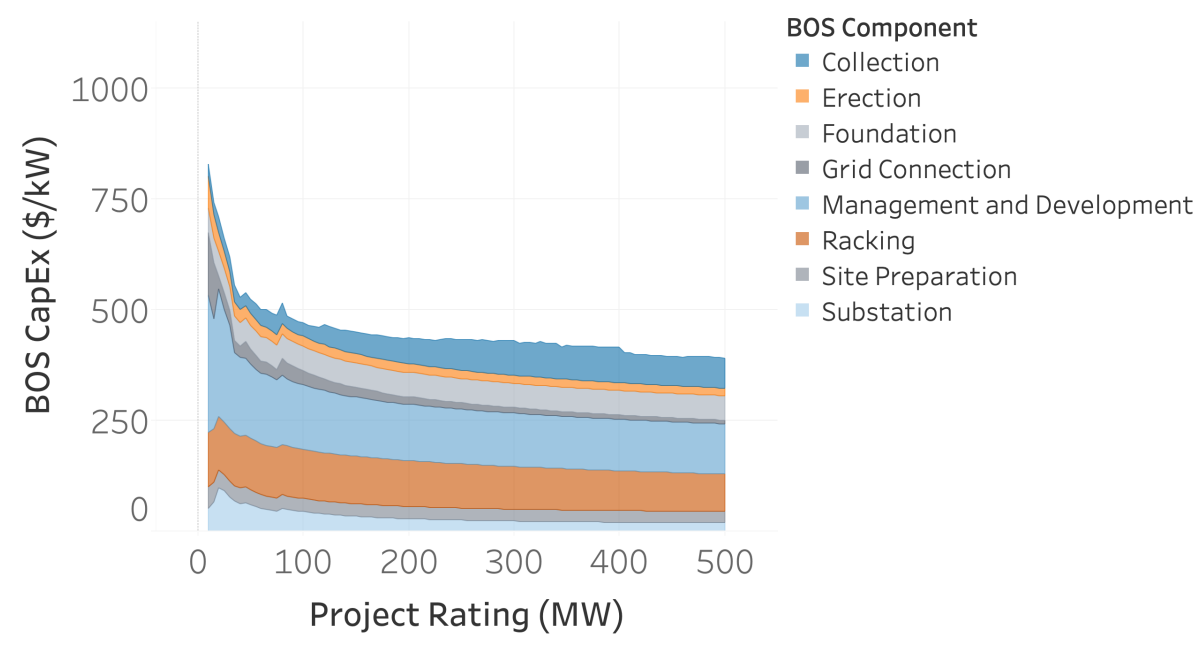

Figure 13. Wind-plus-solar PV HPP BOS component cost breakdown

\subsection{Co-located HPP Vs. Non Co-located Plants}

To identify how much the BOS costs trends for an HPP are driven by colocation, we compared our baseline wind-plussolar PV HPP to a "virtual" hybrid wind-plus-solar PV plant. This analysis revealed BOS cost savings for a colocated hybrid over a virtual hybrid, with level I cost-saving assumptions (representing savings across the management, substation, and grid connection categories) resulting in a 8.6\% reduction in total BOS cost with full interconnection sizing and $10.2 \%$ reduction in cost for the 50\% rated interconnection case (Tables 9 and 10)

Table 9. Potential cost savings by component for 200-MW wind-plus-solar PV virtual hybrid vs. a wind-plus-solar PV HPP using $100 \%$ interconnection rating

\begin{tabular}{|c|c|c|c|c|c|}
\hline \multirow[t]{2}{*}{ BOS Component } & \multirow{2}{*}{$\begin{array}{c}\text { Virtual Hybrid } \\
\text { (Not Colocated) }(\$ / k W)\end{array}$} & \multirow{2}{*}{$\begin{array}{l}\text { HPP (level I Savings) } \\
\text { (Colocated) }(\$ / \mathbf{k W})\end{array}$} & \multicolumn{3}{|c|}{$\begin{array}{c}\text { Savings in BOS Component Cost } \\
\text { Relative to No Sharing }(\%)\end{array}$} \\
\hline & & & level I & level II & Level III \\
\hline Foundation & 55 & 55 & $0 \%$ & $0 \%$ & $0 \%$ \\
\hline Site preparation & 29 & 29 & $0 \%$ & $23 \%$ & $23 \%$ \\
\hline Substation & 43 & 28 & $35 \%$ & $35 \%$ & $35 \%$ \\
\hline Grid connection (trans. \& dist.) & 34 & 17 & $50 \%$ & $50 \%$ & $50 \%$ \\
\hline Collection & 58 & 58 & $0 \%$ & $0 \%$ & $0 \%$ \\
\hline Erection & 19 & 19 & $0 \%$ & $0 \%$ & $5 \%$ \\
\hline Management \& development & 138 & 129 & $7 \%$ & $7 \%$ & $7 \%$ \\
\hline Module racking & 103 & 103 & $0 \%$ & $0 \%$ & $0 \%$ \\
\hline Total & 479 & 438 & $-8.6 \%$ & $-10.1 \%$ & $-10.3 \%$ \\
\hline
\end{tabular}


Table 10. Potential cost savings by component for 200-MW wind-plus-solar PV virtual hybrid vs. a wind-plus-solar PV HPP using $50 \%$ interconnection rating.

\begin{tabular}{|c|c|c|c|c|c|}
\hline \multirow[t]{2}{*}{ BOS Component } & \multirow{2}{*}{$\begin{array}{c}\text { Virtual Hybrid } \\
\text { (Not Colocated) }(\$ / \mathbf{k W})\end{array}$} & \multirow{2}{*}{$\begin{array}{c}\text { HPP (level I Savings) } \\
(\text { Colocated })(\$ / k W)\end{array}$} & \multicolumn{3}{|c|}{$\begin{array}{l}\text { Savings in BOS Component Cost } \\
\text { Relative to No Sharing }(\%)\end{array}$} \\
\hline & & & level I & level II & level III \\
\hline Foundation & 55 & 55 & $0 \%$ & $0 \%$ & $0 \%$ \\
\hline Site preparation & 29 & 29 & $0 \%$ & $23 \%$ & $23 \%$ \\
\hline Substation & 43 & 22 & $49 \%$ & $49 \%$ & $41 \%$ \\
\hline Grid connection (trans. \& Dist.) & 34 & 17 & $50 \%$ & $50 \%$ & $50 \%$ \\
\hline Collection & 58 & 58 & $0 \%$ & $0 \%$ & $0 \%$ \\
\hline Erection & 19 & 19 & $0 \%$ & $0 \%$ & $5 \%$ \\
\hline Management \& development & 138 & 127 & $7 \%$ & $7 \%$ & $7 \%$ \\
\hline Module racking & 103 & 103 & $0 \%$ & $0 \%$ & $0 \%$ \\
\hline Total & 479 & 430 & $-10.2 \%$ & $-11.6 \%$ & $-11.8 \%$ \\
\hline
\end{tabular}

Examining the cost savings achievable with level III component sharing (management, substation, grid connection, site preparation, and crane equipment cost categories), results of which are shown in Figure 14, shows that 10.3\% cost savings is possible with full interconnection sizing, and $11.8 \%$ cost savings is achievable with the $50 \%$ sized interconnection.

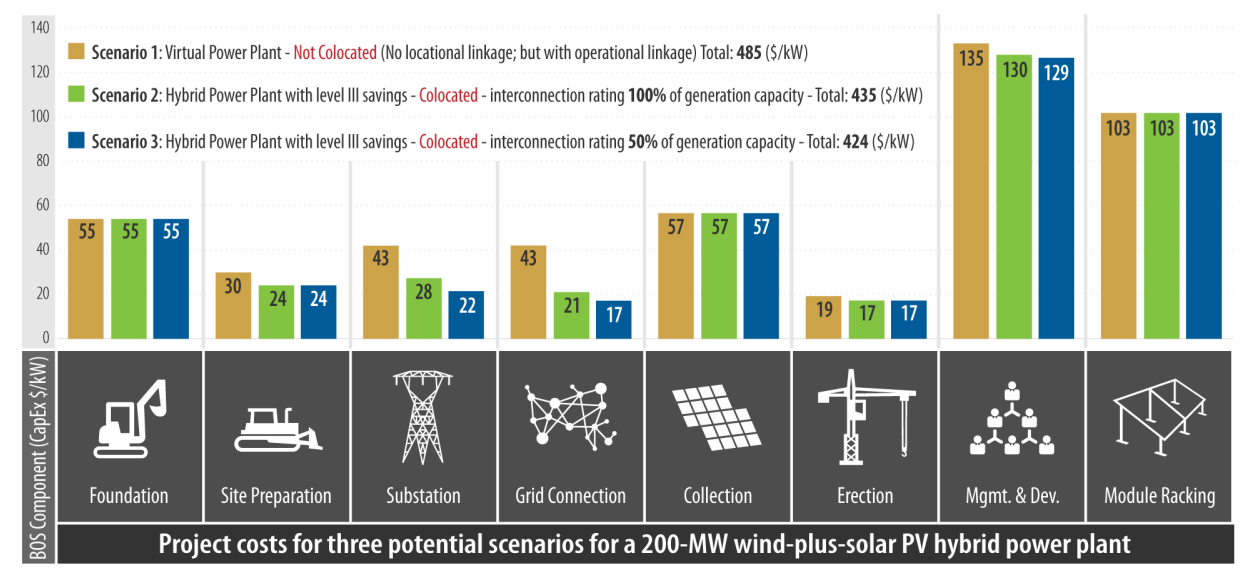

Figure 14. Potential BOS Component Cost Savings for Level III Hybridization of Wind-plus-solar PV

\subsection{Cost Scaling Study}

Figures 15 and 16 shows explore how cost savings may vary with project rating. the percentage of cost savings could be realized by sharing infrastructure at a wind-plus-solar HPP (i.e., the percentage difference in BOS CapEx for a wind-plus-solar PV HPP versus a wind-plus-solar PV virtual hybrid). For example, at a $10 \mathrm{MW}$ project rating, shared infrastructure at an HPP could decrease total BOS CapEx by approximately 17\%. This benefit is somewhat diminished in the $10 \mathrm{MW}-25 \mathrm{MW}$ region because of shared soft cost decreases in wind- or solar-only projects at this size (e.g., only an approximate $7 \%$ reduction via colocation at $15 \mathrm{MW}$ ). The potential for cost reduction via co-location reaches $16 \%$ at the 50-MW plant size. Under the cost scaling and sharing assumptions made in this work, the largest cost reductions for HPPs appear to exist in the 50-200MW range, beyond which there are diminishing returns. Still, colocation continues to offer cost reductions versus non-colocated plants at installed capacities greater than $150 \mathrm{MW}$, with the potential for an approximate 7\% reduction in BOS costs at the 200-MW plant size (the baseline case for the hybrid plant used in this study). 


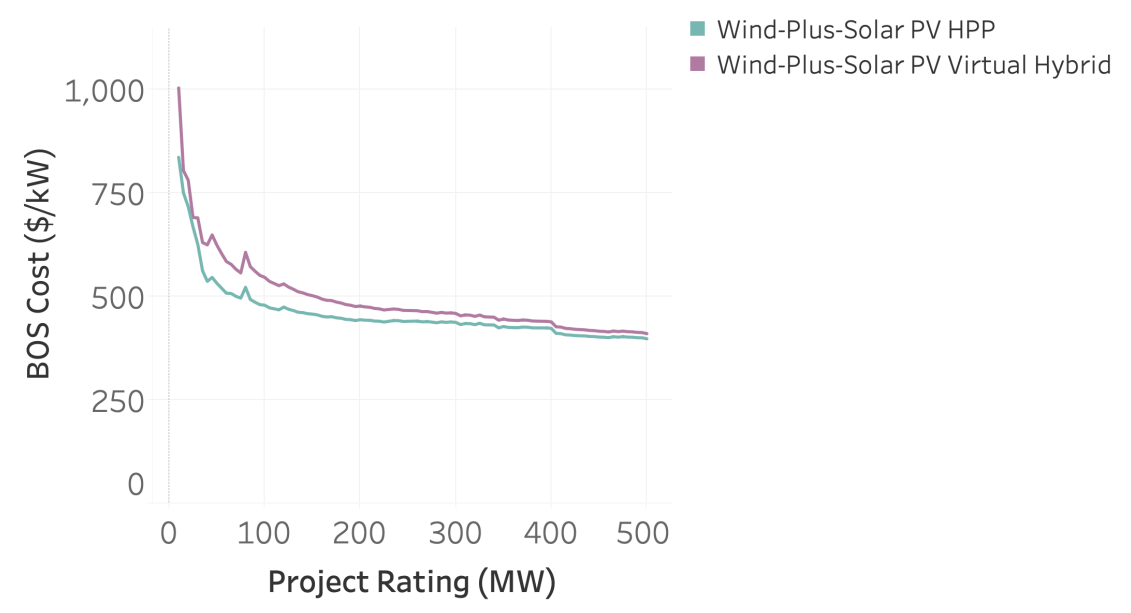

Figure 15. BOS costs for virtual (non-colocated) wind-plus-solar PV hybrid vs. a colocated wind-plus-solar HPP

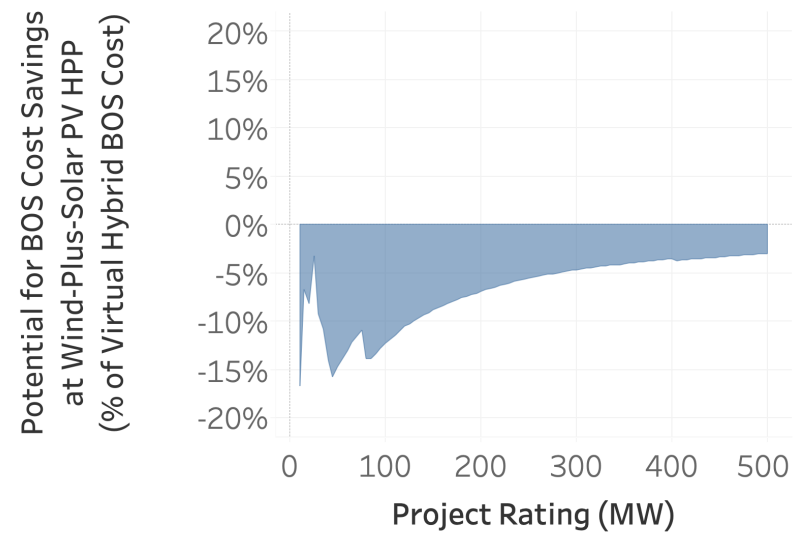

Figure 16. Potential for BOS cost savings at wind-plus-solar PV HPP as compared to a virtual (non-colocated) hybrid

Overall, our results show that reductions in costs associated with grid connection, project substation, and project management represent the main potential areas for cost savings via colocated hybridization. As shown in Figure 16, cost savings reach a peak of approximately $16 \%$ from sharing infrastructure in a colocated PV-plus-wind hybrid plant. 


\section{Conclusion}

Through this work, we outlined the need to study the cost drivers that are specific to hybrid-wind-plus solar PV plants. We analyzed the potential for shared infrastructure cost savings at these colocated HPPs; and we compared the cost savings to virtual, non-colocated plants of equivalent size and technology, elucidating some of the costreduction potential available via colocation. To perform this analysis, we developed a new open-source, Pythonbased cost modeling tool: the Hybrid Balance-of-System Systems Engineering model (HybridBOSSE). The goal of HybridBOSSE is to allow researchers, independent system operators, hybrid plant developers, and government agencies to explore how BOS costs could shape future hybrid plant design.

Using HybridBOSSE, this work mapped out the cost savings achievable through hybridization at a baseline 100-MW wind, 100-MW solar PV, and 200-MW HPP consisting of $100 \mathrm{MW}$ of wind and $100 \mathrm{MW}$ of solar PV on 100-MW and 200-MW interconnections, respectively. Our baseline cost assumptions reveal potential cost savings of $10 \%$ in BOS costs for a 200-MW wind-plus-solar PV HPP versus a virtual (non-colocated) 200-MW wind-plus-solar PV hybrid plant (also consisting of $100 \mathrm{MW}$ of wind plus $100 \mathrm{MW}$ of solar PV), while at certain plant sizes (50MW), savings in BOS cost can reach 16\%. We also showed that the management, racking, and foundation costs are the greatest cost contributors to an HPP across the range of plant scales from 5 MW to $500 \mathrm{MW}$ (Figures 1311 12), and the selection of interconnection sizing can impact these costs (Figure 10).

Given the relatively larger impact of hybridization on the BOS costs of smaller plants in this study, a future study which focuses on the impacts on Distributed Wind would have value.

The capabilities developed in this work have a number of potential applications, including:

- Assessment of scenarios of hybridization, including land sharing, collection system, interconnection sharing, and substation sharing

- Examination of the impact of these scenarios on the cost and configuration of the plant

- Estimation of potential cost savings via co-location or retrofit of existing wind power plants with solar and storage.

In this work we consider the cost-drivers in HPPs, but a more holistic comparison of technology configurations that considers hybrid systems' multiple techno-economic benefits (e.g., shared infrastructure and soft costs, resource complementarity, and plant reliability) is highly recommended. With that in mind, future work will also include:

- Solicitation of industry feedback on cost sharing categories/parameterization.

- Additional scenarios of hybridization, including DC-coupled system designs, and turbine-level integration of electrical conversion equipment and storage.

- Asymmetric sizing of Wind and PV.

- Combining cost saving potential with operational energy generation and cashflow to better understand net economic impacts.

- Regional differences (based on labor cost multipliers, supply chains, terrain, policy and tax changes)

Lastly, given the prevalence of storage in HPPs, future work will involve the inclusion of a battery energy storage system cost model, which will enable wind, solar, storage hybrid plant BOS costs to be effectively modeled. 